\title{
The Patent Dispute Between Apple, Samsung, and Qualcomm: Was Apple, a Good Negotiator?
}

\author{
Shangle Chen ${ }^{1, *, a, \dagger}$ Chang Liu ${ }^{2, *, b, \dagger}$ Jiaming Yang ${ }^{3, *, c, \dagger}$
}

\author{
${ }^{1}$ Shenzhen Vanke Meisha Academy \\ ${ }^{2}$ Economics School of Anhui \\ ${ }^{3}$ Cushing Academy \\ ${ }^{*}$ Corresponding author. Email: ${ }^{a}$ chenshangle@stu.vma.edu.cn, ${ }^{b}$ b51814009@stu.ahu.edu.cn, ${ }^{c} j i y a n g 24 @$ cushing.org \\ These authors contributed equally.
}

\begin{abstract}
The patent dispute is very common in today's business world. For parties involved in such a case they have to formulate comprehensive strategies to obtain the utmost interests. This article reviews and compares two representative cases between Apple, Samsung, and Qualcomm with respect to patent infringement in the past decade. Based on the review, the detailed progress of the negotiation has been delineated. After that, in line with strategic negotiation theories, the practices of Apple are discussed to propose what it has done well and what can be further improved. The results show that negotiation about patent disputes should be more interest-oriented rather than position-oriented. That flexibility is the key to reach a win-win situation for both sides. The reflections and insights put forward by this article would implicate future business negotiations regarding patent disputes.
\end{abstract}

Keywords: business negotiation, patent dispute, Apple, Samsung, Qualcomm.

\section{INTRODUCTION}

Patent infringement is an illegal act with regard to the use of a patented invention without permission from the owners of the patent [1]. Even though violating patent laws is not acceptable, there are massive numbers of disputes in this domain in the business world. Facing such disputes, the lawsuit is considered one of the most effective solutions; however, such lawsuits can become extremely complex when there are tremendous, vested interests lingering among the parties involved in the dispute [1]. In the meantime, the definition of patent infringement may also vary from country to country and sometimes can be very blurry and hard to judge. As a result, all of these factors pose great uncertainties to these lawsuits.

Thus, the patent disputes, in reality, can be said as an extremely complicated process of continuous trade-off and negotiation between the negotiation parties [1]. In this situation, the negotiation strategies become extremely crucial to determine whether problems can be solved effectively. This review article, thereby, attempts to discuss two renowned patent dispute negotiation cases between Apple, Samsung, and Qualcomm. Through the review, this article would shed light on the future business negotiation field, especially about how to solve the disputes regarding the patent among technology companies.

To briefly introduce the parties involved in this case review. Apple Inc. was founded by Steve Jobs and his partners in 1976 and is currently based in California (Figure 1). Apple, to date, is one of the world's largest hardware manufacturers in the fields of personal computers and smartphones, with more than 100,000 employees worldwide. It is also one of the world's largest mobile software and services providers. Its products range from iMac, iPhone, iWatch, and other operating systems and software like App Store, IOS, cloud service, apple music, and payment systems. Apple's revenue is 274.515 billion in 2020 , with the highest stock price among all listed companies in the world. 


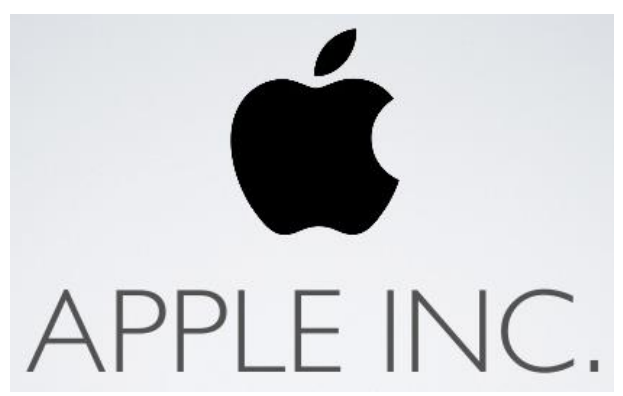

Figure 1. Brand Logo of Apple Inc.

As Apple gradually becomes the technology giant today, it has encountered numerous legal disputes, among which its patent lawsuits with Samsung (Figure 2) and Qualcomm (Figure 3) are two of the most representative ones. More specifically, Apple and Samsung settled a series of legal battles starting from the year 2011. As for the other case with Qualcomm, the world's largest chipset design and manufacturing company, in 2017, Apple officially started the lawsuit against Qualcomm due to its unreasonable license fee. Even, for now, there are also many unsettled issues between the companies.

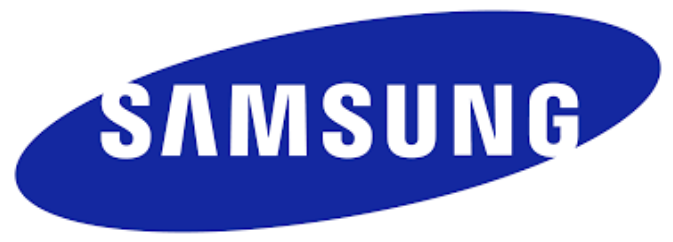

Figure 2. Brand Logo of Samsung

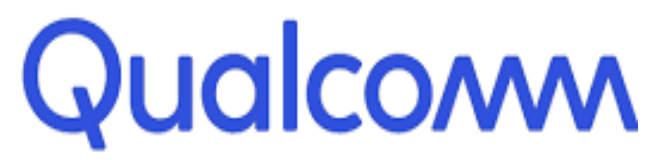

Figure 3. Brand Logo of Qualcomm

All in all, these two cases have been considered representative for the patent dispute; thus, the reflections of how Apple handled these cases may efficaciously implicate the ensuing practices of negotiating the infringement of the patent in today's complex business world. In the following sections, the specific process of these two lawsuits has been reviewed.

\section{THE LAWSUIT BETWEEN APPLE AND SAMSUNG}

The dispute between Apple and Samsung was initiated due to the imitation of the product design of the iPhone and iPad by Samsung [2]. As claimed by Apple, their iconic designs of iPhone and iPad were the results of years of works and millions of investments. However, Apple found that Samsung adopted a similar product design for the Samsung Galaxy phone series. As a response, in April 2011, Apple decided to sue Samsung for the design patent infringement [2].

To strike back, Samsung countersued Apple for the infringement of its mobile communications technologies [2]. Consequently, four months after the first lawsuit, there had already been more than twenty legal disputes between Apple and Samsung in about ten different countries. Since then, this patent war had been heated up. Up to July of 2012, more than fifty lawsuits between Apple and Samsung were in the courts worldwide, being worthy of millions of US dollars [3]. At that same, these lawsuits were on the news headlines everywhere in the world.

As for the results of these lawsuits, it showed a very interesting pattern as those courts in the US favoured Apple while in other parts of the world, such as Japan and Korea, Samsung obtained more supports. For instance, in 2013, Samsung had initially gained the right to ban Apple from selling Apple's products in the US after obtaining support from the US World Trade Commission. However, this decision was finally refused by the Trade Representative from the US after one month [3]. Thus, even though Samsung won the lawsuit, it did not gain any concrete benefits in the US.

As for the tremendous dispute about the design patent of Apple, the first trial in the US announced that Apple would acquire more than 400 million dollars from Samsung; however, the decision was later denied by the US Supreme Court and moved to the US Federal Circuit Court in 2016 for a retrial. For this time, Apple claimed that it should be awarded more than 1 billion dollars from the profit of Samsung. At the same time, Samsung only wanted to pay 28 million as it deemed that this should only be based on the amount directly coming from the patent infringement [4].

In the end, the court made the final decision that Samsung should pay Apple 539 million dollars for infringing Apple's design patent [5]. As to how the patents should be valued, there was no detailed judgment made up to date due to the complex essence of the definition of those design patents. In the end, even though Apple obtained massive financial benefits from Samsung, it did not gain further benefits through this 5year long lawsuit.

\section{THE LAWSUIT BETWEEN APPLE AND QUALCOMM}

After the settlement of the case of Samsung in 2017, a new patent dispute between Apple and Qualcomm was set off in the US. For the reasons of this lawsuit, Qualcomm was firstly sued by Apple that it tried to establish a monopoly of its chip design and production technologies [6]. In detail, Apple claimed that Qualcomm charged extremely high licensing fees from Apple by taking advantage of its huge market power. By initiating 
the lawsuit, Apple hoped that Qualcomm could decrease its patent fees and pay an extra one million for Apple.

At the beginning of this case, Apple was expected to win the lawsuit as Qualcomm had already been fined millions of dollars due to its monopolistic behaviours in other parts of the world. Nevertheless, to strike back, Qualcomm had also inserted massive pressure on Apple by suing Apple for violating its chip patents in Europe and China. Finally, if Qualcomm won these cases, Apple's products would be banned in those countries and would face higher production costs and may decrease the competitive advantages of Apple's product.

The result proved Qualcomm's forecast, in 2019, the jury verdict that Apple infringed three patents of Qualcomm and should pay 31 million and not use those technologies anymore. As a result of this verdict, Apple instantly transformed its negotiation strategy. In April 2019, Qualcomm and Apple together announced an agreement to withdraw all lawsuits between these two corporations worldwide [7]. The agreement is comprised of a penalty payment from Apple to Qualcomm. Besides, they also have reached a six-year licensing agreement and chipset supply agreement. Moreover, they announced that they would strengthen their cooperation in the field of 5G chip development [8].

Since the beginning of the patent dispute, different from the case with Samsung, it lasted for only two years. It ended up in a dismission of the litigation and an agreement of supply and collaboration, which was considered by the public as a constructive ending for both sides [7].

\section{DISCUSSION OF THE NEGOTIATION STRATEGY OF APPLE IN TWO CASES}

First of all, as an evaluation for the effectiveness of Apple's dispute solution with Samsung, according to the law that "you should make the first deal when you know more", Apple did make a good decision. It can be seen that, after Samsung's products were released to the market, Apple detected that these products had infringed their patent rights. Since then, they calculated the total money Samsung gained from these patents and then instantly set out to prosecute. This action helped Apple to avoid more harm from Samsung.

Other than that, it is very wise that Apple made an ambitious offer to the court, which is one billion dollars. That was almost ten more times the amount of the loss than Apple calculated [4]. Making this first offer gave Apple more buffers to argue with Samsung. This strategy proved to be very successful in helping Apple earn a higher money payment than expected. Another thing that Apple did very well was to be "hard on the question, and soft on the person". The infringement of patents is a serious question. Still, Apple only said they decided to prosecute to show their respect to the creativity instead of pursuing a lot of financial profits from this, which helped it obtain more support from the public [3].

However, there was still something that Apple didn't do well. As the results showed, a win-win situation was not achieved, and consequently, Apple's relationship with Samsung was greatly harmed. In the following years, Samsung had ever refused to produce Apple's chip in its factory. When this case just came out, Samsung never wanted to make a patent cross-license agreement. Yet, Apple rejected this option and persisted in asking for the monetary penalty. Finally, this decision led to a more than 6-year long run of the lawsuit, wasting lots of time and financial resources. Even though, in the end, Apple won the lawsuit, the loss of relevant opportunity costs was also extremely high.

Last but not least, in the long run, Apple may have more to lose. People inside and outside the industry have closely watched the patent battle between Apple and Samsung. The U.S. ruling in favor of Apple has also sparked heated debate in the industry. Despite Apple's claim that "the value of innovation has won," its corporations' image as an innovator is beginning to be overshadowed by that of a technology monopolist: the industry is beginning to see Apple as the next Microsoft, accusing it of monopolizing markets, stifle competition and stifle innovation in the name of protecting intellectual property rights. Through lengthy and humorous court arguments, the notion that Samsung phones are just like iPhones has begun to take root in consumers' minds.

Unlike the case between Apple and Samsung, during the lawsuit between Qualcomm, Apple did not decide to insist on its position. As soon as Qualcomm asserted that Apple had infringed several patent rights, Apple reacted very quickly and flexibly. When Apple received Qualcomm's lawsuit, they realized that they might not gain more if they continue to sue Qualcomm. Thus, they instantly paid the monetary penalty to Qualcomm and sought an informal negotiation with Qualcomm [9]. In consequence, the whole dispute was solved in a very efficient manner. More than that, this also forbids the media to make this issue further fermented, maintaining its good market image as well [9]. Furthermore, Apple was also very creative in harnessing this opportunity to develop a partnership with Qualcomm. As can be seen from the results, Apple got the certification from Qualcomm and constructed a long-term relationship with Qualcomm to collaborate on the chip development. As $5 \mathrm{G}$ is coming out, it manifests that the decision to cooperate with Qualcomm definitely helped Apple obtain more competitive advantages in this market, enabling its ability to keep competing with other cell phone manufacturers like Samsung and Huawei [9].

On the side of Qualcomm, through this settlement, Qualcomm has not only achieved the purpose of maintaining its core business model but also 
demonstrated the rationality, certainty, and stability of its business model to the outside world through the hand of Apple, and almost eliminated the possibility of any threat of lawsuits to overturn its business model in the future [10]. The six-year technology licensing agreement, which includes an option to extend for two years, essentially ties Apple into Qualcomm's boat. More importantly, the road to Apple's base belt in the short term is basically blocked [11]. Therefore, looking at the case as a whole, it can be deemed that Apple's flexibility successfully resulted in a win-win situation for both Apple and Qualcomm.

\section{REFLECTION AND CONCLUSION}

To make a reflection and conclusion of the above review and discussion, it can be said that how to cope with the patent dispute should never be solely regarding the patent itself. Instead, it is necessary to view the negotiation as a comprehensive interests bargaining process. In other words, even though the patent holder may win the lawsuit, they would face other drawbacks such as negative media exposure, high financial and time cost and the broken relationship with other business partners, especially when it does not have ample competitive advantages to survive in the market by itself. Even as powerful as Apple, it needs collaboration and supports from the industrial patterners. All in all, the solutions of handling patent disputes should comprehensively consider all the influential factors before making the lawsuit. Just as previous studies concluded, the patent in nowadays technology field should be viewed as a marketplace in which all the decision-making have to be made with trade-offs [12].

Putting it in another way, the negotiation of patent infringement should be fully interest-based other than position-based. In this situation, the patent violation can be deemed a bargaining power to achieve more benefits rather than merely the financial payback. As shown in this article, being flexible is very significant to handle all types of patent disputes. After all, in today's business world, every player has to some extent rely on others' patents. Thus, when one finds that its patent right is infringed, it might be a precious opportunity to make a negotiation for further collaboration to reach a win-win solution for both sides.

Finally, in terms of the implication for future research, it is suggested that future studies can conduct comprehensive case studies to detect what specific strategies are adopted during the interest-based negotiation process. Also, empirical studies to measure the costs and benefits during the negotiation are also necessary so as to summarize some best practices for patent management for tech companies.

\section{REFERENCES}

[1] Bessen, J. E., \& Meurer, M. J. (2006). Patent litigation with endogenous disputes. American Economic Review, 96(2), 77-81.

[2] Cusumano, M. A. (2013). The apple-samsung lawsuits. Communications of the ACM, 56(1), 2831.

[3] Kim, S. Y., Park, S. T., \& Kim, Y. K. (2015). Samsung-Apple patent war case analysis: focus on the strategy to deal with patent litigation. Journal of digital convergence, 13(3), 117-125.

[4] Gil, E. M. (2016). Samsung v. Apple: Taking a bite out of the design patent article of manufacture controversy. U. Miami Bus. L. Rev., 25, 67.

[5] Samuelson, P. (2016). Apple v. Samsung and the upcoming design patent wars?. Communications of the ACM, 59(7), 22-24.

[6] Saardchom, N. (2014). Design patent war: Apple versus samsung. South Asian Journal of Business and Management Cases, 3(2), 221-228.

[7] Ai, Y., \& Lu, T. Y. (2019). On the Rationality of Bundled Rebate Program in Modem Chip Industry: an Analysis on Qualcomm's Case. Journal of Industry, Competition and Trade, 19(4), 641-660.

[8] Cusumano, M. A. (2010). Staying power: Six enduring principles for managing strategy and innovation in an uncertain world (lessons from Microsoft, Apple, Intel, Google, Toyota and more). Oxford University Press.

[9] Stern, R. H. (2017). FTC and Apple Sue Qualcomm for Cell Phone Standardization Skullduggery, Part 2: Apple's Claims. IEEE Micro, 37(4), 72-81.

[10] Ginsburg, D. H., \& Wright, J. D. (2019). A Bargaining Model v. Reality in FTC v. Qualcomm: A Reply to Kattan \& Muris. Reality in FTC v. Qualcomm: A Reply to Kattan \& Muris (May 15, 2019).

[11] Brunner, J. (2014). Patent Prosecution as Dispute Resolution: A Negotiation Between Applicant and Examiner. J. Disp. Resol., 7.

[12] Giordano-Coltart, J., \& Calkins, C. W. (2007). Best practices in patent license negotiations. Bioentrepreneur, 1-3. 